\title{
A Review- Remote Sensing
}

\author{
Balaji Waghmare*, Madan Suryawanshi** \\ *Department of Geography, Dr. Babasaheb Marathwada University, Aurangabad [MS], India. \\ **Department of Geography, Dr. Babasaheb Marathwada University, Aurangabad [MS], India.
}

\begin{abstract}
Now-a-days the field of Remote Sensing and GIS has become exciting and glamorous with rapidly expanding opportunities. Many organizations spend large amounts of money on these fields. Here the question arises why these fields are so important in recent years. Two main reasons are there behind this. 1) Now-a-days scientists, researchers, students, and even common people are showing great interest for better understanding of our environment. By environment we mean the geographic space of their study area and the events that take place there. In other words, we have come to realize that geographic space along with the data describing it, is part of our everyday world; almost every decision we take is influenced or dictated by some fact of geography. 2) Advancement in sophisticated space technology (which can provide large volume of spatial data), along with declining costs of computer hardware and software (which can handle these data) has made Remote Sensing and G.I.S. affordable to not only complex environmental / spatial situation but also affordable to an increasingly wider audience.
\end{abstract}

\section{INTRODUCTION}

Literally Remote Sensing means obtaining information about an object, area or phenomenon without coming in direct contact with it. If we go by this meaning of Remote Sensing, then a number of things would be coming under Remote Sensor, e.g. Seismographs, fathometer etc. Without coming in direct contact with the focus of earthquake, seismograph can measure the intensity of earthquake. Likewise without coming in contact with the ocean floor, fathometer can measure its depth. However, modern Remote Sensing means acquiring information about earth's land and water surfaces by using reflected or emitted electromagnetic energy.From the following definitions, we can have a better understanding about Remote Sensing: According to White (1977), Remote Sensing includes all methods of obtaining pictures or other forms of electromagnetic records of Earth's surface from a distance, and the treatment and processing of the picture data... Remote Sensing then in the widest sense is concerned with detecting and recording electromagnetic radiation from the target areas in the field of view of the sensor instrument. This radiation may have originated directly from separate components of the target area, it may be solar energy reflected from them; or it may be reflections of energy transmitted to the target area from the sensor itself.

\section{HISTORY OF REMOTE SENSING}

The knowledge about the history of Remote Sensing is necessary for better understanding of the subject and its scope, and also for future development, particularly for the welfare of human society. The development of remote sensing over time can be broadly divided into following six phases.

\section{Phase I (Up till 1920): Initial Phase}

Man always inquisitive about the things across a forest or a mountain, which he cannot see directly. So, since time immemorial man has always tried to reach greater heights, such as tree tops, mountains etc. to observe phenomena of his interest on the earth surface, viz. to decide habitat places, farming and other day-to-day activities. This inquisitiveness to get a bird's eye view prompted man to take photographs of earth from elevated platforms. So, the initial photographs of earth were captured from elevated platforms on the surface of the earth. However, the actual beginning of Remote Sensing can be traced back in 1958, when free balloons were used for photography by the French Gaspard Felix Tournachon (known as Nadar) to photograph the village of Petil Becetre near Paris. In 1860, a part of Boston and Massachusetts were photographed from a captive balloon at 1200 feet height in USA. In 1909, the first aerial photograph was taken from an aero plane, piloted by Wilbur Write over Centocelli, Italy. World War I provided a boost in the use of aerial photography. During that time, aerial photographs were used for two purposes - spying and mapping [15].

Phase II (1920-1945): Development of Platforms and Sensors

Improvement in aero planes, cameras, films etc. resulted in the development of aerial photography 
during this period. The proper planning of flight for photographic purpose was also started. Topographical mapping was the main thrust of the aerial photography. However, a number of scientists like geologists, botanists, soil scientists, geographers began interpreting the photographs to get information of their interest, especially for development of natural resources. During this period photographic coverage were increased both on the large and medium scale. World War II gave a real boost to photointerpretation technique, which was widely used for military intelligence purposes. The mapping of strategic location, military targets and assessments of damages could be done accurately [6-8].

\section{Phase III (1945-50): Development of Teaching and Training}

After World War II, much emphasis on teaching and training of this technique was given due to previous experience of its wide use in different spheres. Many courses on Remote Sensing were started in reputed universities of United States and Western European countries. A commission on the utilization of aerial photographs was set up by International Geographical Union (IGU) in 1949. The members of the commission emphasized the need of knowledge of those parts of world which were not earlier photographed and also attention was given to cover more area by aerial photographs and techniques essential for interpretation [8-10].

\section{Phase IV (1950-60): Development of Instruments for Interpretation}

In this phase, the techniques of photo interpretation became much more an applied technique. A number of instruments was developed and introduced for interpretation during this period, which may be termed as a landmark in the progress of these techniques. It opened a new horizon for accurate and fast analysis and also for monitoring the changes. Hence a considerable advanced interpretation was made in many disciplines such as Geography, Geology, Geophysics, Agriculture and Archaeology.

\section{Phase V(1960-1985): Significant Phase}

This phase is very significant in the history of Remote Sensing as artificial satellites were launched in the space for acquiring information of earth surface. Though two American satellites, i.e. Explorer I and II were launched in 1958 and 1959 respectively under Explorer and DiscoverProgramme, they were not important from Remote Sensing point of view. On $1^{\text {st }}$ April, 1960, one satellite of eight members of TIROS (Television and Infrared Observation Satellites) family was launched as a research and development project. As TIROS's name suggested, the satellite carried two types of sensing devices - firstly, television, camera etc. which took picture of the visible spectrum; and secondly, infrared detectors which measured the non visible part of spectrum and provided information of local and regional temperature of earth's surface. The supply of remotely sensed data of earth surface was greatly increased with the launching of ERTS-I (Earth Resources Technology Satellite) on $23^{\text {rd }}$ July, 1972. It was placed in a sunsynchronous polar orbit about 600 miles above the earth surface. It makes 14 revolutions in a day around the earth and its sensors were covering a series $160 \mathrm{kms}$. wide strip. Then it was followed by ERTS-2 in 1975. With the launch of this satellite, the name of these satellites has been changed from ERTS-1, 2 to LANDSAT-1, 2 respectively. Four other satellites in these series were launched one after another in this phase, with improved cameras and sensors. Beside this, many other satellites were launched in the space by European and Asian Countries during this period [1014].

\section{Phase VI (1985 onwards): Recent Development Phase}

In this period, Remote Sensing technique has been improved in two ways. Firstly, there have been developments of sensors which can use infrared and microwave spectrum other than visible spectrum to get information about earth's surface. Secondly, there have been very important advances with respect to the platforms in which sensors are mounted. Besides, satellites have been launched for specific purposes and with specific capability. The ground resolution is continuously increasing till today. Hence, interpretation and mapping is becoming very easy, accurate and purposive. The European Radar satellite (ERS-I) launched in 1991 opened the avenue for systematic global observation in the microwave region. The French Satellite 'SPOT' is producing the imagery to provide the three dimensional view under stereoscope. The satellite - IKONOS, launched on $24^{\text {th }}$ September, 1999 has $1 \mathrm{~m}$. resolution in panchromatic and $4 \mathrm{~m}$. resolution in multi-spectral cameras. USA, France and India have planned a series of satellites, with improved capability, so that the users are assured continuity of data [13][14].

\section{CONCLUSIONS}

Remote sensing and GIS are integral to each other. The development of Remote Sensing is of no use without the development of GIS and vice versa. Remote Sensing has the capability of providing large amount of data of the whole earth and also very frequently. GIS has the capabilities of analyzing a large amount of data within no time. These voluminous data would have become useless without the development of GIS. Manual handling of one time remote sensing data would take years together, 
by the time a number of multi date data would have piled for analysis. Likewise capability of GIS would have no use without the development of Remote Sensing technology, which provides voluminous data.

\section{REFERENCES}

[1] Allen, T. R., \& Kupfer, J. A., 2000. Application of spherical statistics to change vector analysis of landsat data: Southern appalachian spruce - Fir forests. RS. Env, 74(3), 482-493.

[2] Anderson, G. L., Everitt, J. H., \& Escobar, D. E., 1996. Mapping leafy spurge (Euphorbia esula) infestations using aerial photography and geographic information systems. Geocarto International, 11(1), pp. 81-89.

[3] Anderson, G. L., Everitt, J. H., Richardson, A. J., \& Escobar, D. E., 1993. Using satellite data to map false broomweed (Ericamera austrotexana) infestations on south Texas rangelands. Weed Technology, 7, pp. 865871.

[4] Barrett, E. C., 1980. Satellite monitoring of conditions conducive to the upsurge of insect pests. in: Satellite remote sensing. Applications to rural disasters. Proc. Joint ESA/FAO/WMO training course, Rome.

[5] Giacomo Capizzi, Grazia Lo Sciuto, Marcin Wozniak, Robertas Damasevicius: A Clustering Based System for Automated Oil Spill Detection by Satellite Remote Sensing, ICAISC (2) 2016: 613-623

[6] Schowengerdt, Robert A. (2007). Remote sensing: models and methods for image processing (3rd ed.). Academic Press. p. 2. ISBN 978-0-12-369407-2.

[7] Schott, John Robert (2007). Remote sensing: the image chain approach (2nd ed.). Oxford University Press. p. 1. ISBN 978-0-19517817-3.

[8] Guo, Huadong; Huang, Qingni; Li, Xinwu; Sun, Zhongchang; Zhang, Ying (2013). "Spatiotemporal analysis of urban environment based on the vegetationimpervious surface-soil model" (Full text article available). Journal of Applied Remote Sensing. 8: 084597. Bibcode: 2014JARS....8.4597G. doi:10.1117/1.JRS.8.084597.

[9] Liu, Jian Guo \& Mason, Philippa J. (2009). Essential Image Processing for GIS and Remote Sensing. Wiley-Blackwell. p. 4. ISBN 978-0-470-51032-2. "Saving the monkeys". SPIE Professional. Retrieved 1 Jan 2016.
[10] Howard, A., et al., (Aug 19, 2015). "Remote sensing and habitat mapping for bearded capuchin monkeys (Sapajus libidinosus): landscapes for the use of stone tools". Journal of Applied Remote Sensing. 9 (1). doi:10.1117/1.JRS.9.096020.

[11] http://hurricanes.nasa.gov/earthsun/technology/remote_sensing.html

[12] Mills, J.P.; et al. (1997). "Photogrammetry from Archived Digital Imagery for Seal Monitoring". The Photogrammetric Record. 15 (89): 715-724. doi:10.1111/0031868X.00080.

[13] Twiss, S.D.; et al. (2001). "Topographic spatial characterisation of grey seal Halichoerus grypus breeding habitat at a sub-seal size spatial grain". Ecography. 24 (3): 257-266. doi:10.1111/j.1600 0587.2001.tb00198.x.

[14] Stewart, J.E.; et al. (2014). "Finescale ecological niche modeling provides evidence that lactating gray seals (Halichoerus grypus) prefer access to fresh water in order to drink". Marine Mammal Science. $\quad 30 \quad$ (4): $1456-1472$. doi:10.1111/mms. 12126 . 